\title{
Engagement Cross-Disciplinary Research in Africa
}

\author{
Cesar Fortes-Lima, Ezekia Mtetwa, and Carina Schlebusch \\ (editors of this book)
}

Scientific articles included in this conference proceedings were all presented at the "Africa, the cradle of human diversity" international conference during May 22nd-25th 2019, held at Uppsala University, Sweden (https://africathecradle ofhumandiversity.com). At this conference, leading researchers presented and discussed new results and multidisciplinary approaches to address longstanding questions about human evolutionary history and population dynamics in Africa and beyond. The conference covered an extensive time range in human evolution, starting with the evolution of early humans in Africa to the complex cultural and genetic diversity of ancient and modern African populations. In this international event, participants were from a wide range of academic backgrounds with $52 \%$ attendees and $48 \%$ invited speakers being female, and $31 \%$ from under-represented countries.

To present recent knowledge and ongoing research in Africa from a multidisciplinary perspective, ten articles on a range of topics and themes are presented in this conference proceedings, and they are structured around three main themes. In the first section, two papers are incorporated in the "Early Humans in Africa" theme. Both studies focus on paleoanthropological research in Africa to better understand the origins of our species, and human biological and behavioral evolution.

In Chapter 1 (entitled "A southern African perspective on human origins research between 500 ooo and 50 ooo years ago: Current dilemmas and questions for the future"), Marlize Lombard gives us an overview of the African fossil and archaeological record, spanning the Earlier to Middle Stone Age periods (50o kya to 5 o kya). Although concentrating on southern Africa, the author put fossil discoveries across the continent in context and discuss the behaviors and cultural development of various Homo species across time and space. To weave together a composite story of the last 5 oo thousand years of our species' evolution, the author brings together recent findings from different disciplines: archaeology, paleoanthropology, genetics and cognitive anthropology.

In Chapter 2 (entitled "Further notes on the Ngaloba Industry, a Middle Stone Age Assemblage Directly associated with early Homo in the Greater Laetoli, northern Tanzania"), Fidelis T. Masao and Jackson S. Kimambo discuss

(C) CESAR FORTES-LIMA ET AL., 2022 | DOI: 10.1163/9789004500228_002

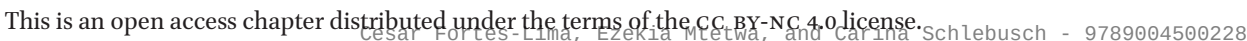


new field data suggesting that the Ngaloban Middle Stone Age (MSA) lithic industry had considerable spatial diversity across the Greater Laetoli area of northern Tanzania than previously imagined. The authors reveal that previous research at the Ngaloba sites had overlooked the spatial distribution and occurrence of human activities during the MSA period in the Greater Laetoli and its surrounding areas. They also note that studies in the Laetoli locality, famous for its earliest hominid footprints and other materials indicating human cultural and biological evolution, had recurrently focused on artifacts identified as MSA, overlooking those suspected to be Later Stone Age (LSA). In this paper, the authors provide results of their recent fieldwork, aimed at understanding the cultural expressions of the early humans associated stratigraphically with the Ngaloba MSA assemblages. Their results, which included MSA materials, but also a sizeable amount of artifacts that could be described as LSA, open a new discussion in which the authors point out that the latter assemblage point to the possible existence of technological variation and diversity in the Greater Laetoli area, particularly between lowland and highland industries during the MSA period.

In the second section, four articles are incorporated in the "Cultural transitions in Africa" theme, to present a closer look at ancient communities from different locations, their lithic technologies, and cultural transitions from the Stone Age to the Iron Age in Africa.

In Chapter 3 (entitled "West-Central African diversity from the Stone Age to the Iron Age, continuities and transitions during the Late Pleistocene and the Holocene"), Bernard Clist presents a new comprehensive review of the archaeology of peoples who have inhabited Central Africa from the Middle Stone Age through the Iron Age to historical times. This chapter highlights high cultural diversity in Central Africa for the last 30,00o years. It also puts into perspective the available information related to ancient exchange networks, often over long distances, connecting various archaeological cultures. Further, the author reviews the social complexity found in the northwestern part of the region during the first half of the first millennium AD illustrated by small cemeteries in Cameroon, Equatorial Guinea, and Gabon. In addition, the author found sharp discontinuities in some cultural sequences, which are better interpreted as slow changes over several generations from the Neolithic to modern times indicating long-term traditions. Lastly, the author shows the need for local palaeoenvironmental sequences to complement the developing archaeological record.

In Chapter 4 (entitled "Ancient urban assemblages and complex spatial and socio-political organization in Iron Age archaeological sites from Southern Africa"), Plan Shenjere-Nyabezi and Gilbert Pwiti revisit the spatiotemporal 
development of drystone-walled urban settlements in southern Africa between the 11th and 19th centuries AD. Using a framework combining archaeological, architectural and spatial studies, as well as a combination of Costly Signalling, Assemblage and Actor Network Theories, the authors offer refreshed insights into the rise and fall of the Zimbabwe Culture. Moving away from function and use, the authors invite attention to the complex socio-political, ideological and economic processes as critical factors to consider for an account of the development of monumentality in southern Africa. Their broadened view in terms of time and space, as well as a strong component of interdisciplinary approaches, reinvigorates discussions and interpretations of the Zimbabwe Culture. Again, the authors' recent fieldwork in northwestern Zimbabwe further reveals a greater spatiotemporal complex and ambiguity into the stonebuilt settlements than previously defined.

In Chapter 5 (entitled "Diversity and variability in the preindustrial iron-smelting technologies of Great Zimbabwe, Southern Africa"), Ezekia Mtetwa draws attention to the iron industry of the famous site of Great Zimbabwe in southern Africa, overshadowed in research by the recurrent focus on the settlement's spectacular architecture. The author underscores the significance of iron in the socio-political and economic transformation of the agro-pastoral and trading societies of Great Zimbabwe. The author discusses the significance of the overlooked archaeological landscape surrounding Great Zimbabwe, revealing new archaeological data for the existence of a considerable iron industry that employed a diversity of innovative designs and processes for smelting iron. The author also discusses the spatial variability of iron production activities in Great Zimbabwe, some taking place within settlements. Using these new data sets, the author argues that the nature and social organisation of precolonial iron technology in Great Zimbabwe specifically, and sub-Saharan Africa as a whole, were more complex and ambiguous in time and space than previously thought.

In Chapter 6 (entitled "Grappling with diversity in livestock-related, nonagriculturist archaeology in the light of genetic research into the Lactase persistence allele, $-14010^{*} \mathrm{C}$, in southern Africa"), Thembi Russell and Faye Lander discuss the introduction of pastoralist practices to southern Africa and its connection with adaptation to milk drinking. The authors compare archaeological evidence of livestock on the southern African landscape with genetic evidence in the form of frequency distributions of the $-14010 \mathrm{C}$ lactase persistence allele across southern African populations. They also integrate climatic factors and environmental influences (such as diseases) into their discussions and contribute ethnographic accounts of livestock herding histories. By combining evidence from these diverse fields, they highlight the 
importance and unsolved questions of milch pastoralism in the drier western half of southern Africa.

In the third section of the book, four articles are incorporated in the "Genomic research of ancient and modern populations in Africa" theme. In this section, ancient and modern-day DNA studies are reviewed and discussed, with regards to their contribution to inferences about population diversity and human history on the African continent, as well as the utility of genetics to health and disease-related research in Africa.

In Chapter 7 (entitled "Paleogenomics of the Neolithic transition in North Africa"), Rosa Fregel examines the so-called Neolithic revolution that started in the Fertile Crescent around 13,000 BCE and expanded from there to North Africa. The author shows how paleogenomics studies have proved to be a powerful source for providing new evidence to address long-standing questions about the Neolithic transition and migration dynamics. Although most of the paleogenomics research has been performed in European populations, the author highlights how recent paleogenomics studies in North Africa have started to shed light on the change from hunter-gatherer to farming societies. The author previously investigated ancient DNA data that evidenced how Early Neolithic people from Morocco are genetically similar to Upper Paleolithic individuals, while late Neolithic individuals from North Africa are admixed with a North African and a European component. In addition, in this review of paleogenomics studies in North Africa, the author also discusses the development of complex Epipaleolithic communities and the migration of farmers from Europe.

In Chapter 8 (entitled "Ancient DNA studies and African population history"), Mário Vicente and Carina Schlebusch present a review of the history and utility of ancient DNA studies in the framework of other disciplines that study human history. They furthermore discuss the African ancient DNA studies published to date and present a meta-analysis of ancient DNA data, in the context of modern-day genetic variation. They furthermore tie-in the genetic analyses and inferences with observations from the fields of archaeology, linguistics and palaeoanthropology. They also point to current caveats and discrepancies and suggest how future research can try to overcome current difficulties in the field. Through these discussions and interpretations, current African ancient DNA research is put into the perspective of cross-disciplinary research regarding human history inference.

In Chapter 9 (entitled "The $\mathrm{H}_{3}$ Africa Consortium: Publication outputs of a pan-African genomics collaboration (2013 to 2020)"), Ananyo Choudhury, Dhriti Sengupta, Shaun Aron and Michèle Ramsay provide a comprehensive review of 
the scientific and academic activities at the Human Heredity and Health in Africa ( $\mathrm{H}_{3}$ Africa) Consortium. Over a 7-year period $\mathrm{H}_{3}$ Africa has expanded its pan-African network to 30 countries. This outstanding African-led initiative is highly complex and includes a pan-African bioinformatics research network to investigate population genomics, non-communicable and infectious diseases, and the microbiome in several African regions, as well as ethics projects and community engagement. The authors show the strong focus of $\mathrm{H}_{3}$ Africa on capacity strengthening and the genomics publications, and how they are currently steadily increasing, with outputs shifting from an emphasis on reviews and perspectives to original and groundbreaking research publications. To review the fruitful list of publications of the $\mathrm{H}_{3}$ Africa Consortium, the authors analyse the core publications under specific themes that reflect the areas of activity. In addition to scientific knowledge, the $\mathrm{H}_{3}$ Africa Consortium is making available for the international scientific community extensive genomic and phenotype data and the stored biospecimens of three Biorepositories. These resources would to notably increase our understanding of demographic processes that shaped the diversity of African populations, and health and disease in Africa and across the world.

In Chapter 10 (entitled "Disentangling the impact of the transatlantic slave trade in African Diaspora populations from a genomic perspective"), Cesar Fortes-Lima discusses the population history and admixture dynamics of African Diaspora populations that had undergone the transatlantic slave trade. The author focuses on recent genome-wide studies that use genomic information of ancient and modern-day African-descendant populations to complement and validate historical and archaeological resources. These studies have unravelled the ancestral origins of African-descendant populations from North America (in the USA), South America (in French Guiana and Suriname), and the Caribbean (in Cuba). The author also examines paleogenomics research that delves deeper into the living conditions and migration routes of enslaved Africans during the slave trade period by using aDNA generated with and without human skeletal remains. Overall, this chapter helps us to better understand one of the darkest chapters of human history shed new light on the demographic history of enslaved African-descendant populations, and by examining paleogenomics research brings forgotten histories of enslaved Africans back to life.

Together, chapters from the three main themes are a valuable source of information for the general audience and academic scholars interested to investigate African human diversity, and highly encourage a multidisciplinary perspective to understand the history of human populations in the African continent as well as the African Diaspora. 


\section{Editor's Acknowledgements}

This edited volume is based on presentations and discussions at the "Africa, the cradle of human diversity" international conference held at Uppsala University, Sweden. The editors are extremely grateful to all the authors who contribute to this book, as well as to all the speakers and participants at the event. Our special thanks go to Cecile Jolly, Mário Vicente, Rickard Hammarén, and Imke Lankheet for organizational support during the conference. We are grateful to the European Research Council (ERC-2017-STG grant: AfricanNeo), the Swedish Research Council (grant reference number: 2018-o6734), the Wenner-Gren Foundation, and the Riksbankens Jubileumsfond Foundation for supporting the conference.

\section{Editorial Note}

The contributions of this book were originally submitted in early 2020 , and therefore do not incorporate subsequent developments in scientific research. For citations that were included as "in press" or "in preparation" at the time of submission and were later published during the review of the book, those citations were later updated accordingly with the date and journal of the publication. 